\title{
THE AMOUNT OF WATER REQUIRED TO DECREASE THE CRITICAL TENPERATURE DIFFERENCE OF A STANDING WAVE THERMOACOUSTIC ENGINE
}

\author{
K. Tsuda ${ }^{* *}$ and Y.Ueda ${ }^{1}$ \\ ${ }^{1}$ Graduate School of Bio-Application and System Enginnering, Tokyo University of Agriculture and Technology, \\ 2-24-16 Nakacho, Koganei-shi, Tokyo, Japan. \\ *Corresponding author's e-mail: 50014701202@st.tuat.ac.jp
}

Keywords: Thermoacoustic engine, standing wave, the low critical temperature, water, vapor, twophase fluid.

\begin{abstract}
It is well known that the critical temperature difference needed for causing a thermoacoustic oscillation is decreased by the presence of water. R. Reilgh described in his book "Theory of sound" [1] that "the production of sound is facilitated by the vapor in the notice of glassblowers" and the Kibitsunokama, which is used in Japanese ritual, can generate sound wave by using a rice-grain regenerator and water vapor ${ }^{[2,3]}$. Furthermore, D.Noda and Y.Ueda demonstrated that water vapor reduces the critical temperature difference from 290 to 56 degree $\mathrm{C}^{[4]}$. However, it has not been found how much water is necessary for the decrease of the critical temperature difference. In this study, we measured the critical temperature difference of a standing wave thermoacoustic engine as a function of the water mass added into the working gas. We increased the water mass from $0 \mathrm{~g}$ in increment of $0.05 \mathrm{~g}$. As a result, the critical temperature difference was not changed in the range from $0 \mathrm{~g}$ to $0.15 \mathrm{~g}$. On the other hand, when the water mass was $0.20 \mathrm{~g}$, the critical temperature difference was decreased from 144 to 54 degree $C$. Therefore, it is found that the marginal value of the amount of water required to decrease the critical temperature difference exists. Moreover, we measured the marginal mass of water with changing material of a regenerator.
\end{abstract}

\section{References}

[1] Rayleigh, J.W.S. “Theory of Sound”, Dover Publications, Second, (1945), 230-231.

[2] Ueda, A. "Ugetsu monogatari", (1776), Kyoto, Japan.

[3] Ueda, Y. "Kibitsunokama -instrument used in historical Japanese shrine ritual-", The $2^{\text {nd }}$ International Workshop on Thermoacoustics, SD-1, (2014), Sendai, Japan.

[4] Noda, D and Ueda, A. "A thermoacoustic oscillator powered by vaporized water and ethanol", Am. J. Phys., 81(2), (2013), 124-126. 